\title{
,ance \\ Complicated Mandible Fracture Treatment with Xenogenic Bone Graft
}

\author{
Ekaterina Yu Diachkova ${ }^{1, *(\mathbb{D}}$, Sofia V. Popova ${ }^{2}$, Liana D. Arazashvili ${ }^{2}$, Pavel Sergeevich Petruk ${ }^{2}$ \\ and Igor V. Cherkesov ${ }^{2}$
}

Citation: Diachkova, E.Y.; Popova, S.V.; Arazashvili, L.D.; Petruk, P.S.;

Cherkesov, I.V. Complicated

Mandible Fracture Treatment with

Xenogenic Bone Graft. Appl. Sci. 2022,

12, 2384. https://doi.org/10.3390/

app12052384

Academic Editors: Stefano Gennai and Morena Petrini

Received: 15 January 2022

Accepted: 21 February 2022

Published: 24 February 2022

Publisher's Note: MDPI stays neutral with regard to jurisdictional claims in published maps and institutional affiliations.

Copyright: (c) 2022 by the authors. Licensee MDPI, Basel, Switzerland. This article is an open access article distributed under the terms and conditions of the Creative Commons Attribution (CC BY) license (https:// creativecommons.org/licenses/by/ $4.0 /)$.
1 I.M. Sechenov First Moscow State Medical University (Sechenov University), 8-2 Trubetskaya Str., 119991 Moscow, Russia

2 Department of Maxillofacial Surgery, Borovsky Institute of Dentistry, I.M. Sechenov First Moscow State Medical University (Sechenov University), 8-2 Trubetskaya Str., 119991 Moscow, Russia; doctorsofia@yandex.ru (S.V.P.); arazashvili@mail.ru (L.D.A.); petruk_pavel@yahoo.com (P.S.P.); cherkesovi@gmail.com (I.V.C.)

* Correspondence: secu2003@mail.ru

\begin{abstract}
The problem of filling bone cavities remains relevant in maxillofacial and oral surgery. There is a large selection of osteotropic materials, of various natures, for filling bone defects of different etiologies. The aim of our research was to improve the outcome of surgical treatment in a patient with a complicated mandibular fracture, with the use of a collagenic xenograft during osteosynthesis. In this article, we share our experience of the treatment of a patient with a complicated mandibular angle fracture, in combination with a follicular cyst. The obligate steps of treatment included stabilization of the bone fragments, decreasing the risk of fracture line malposition, using titan mini-plates, and shortening the time of bone regeneration, by filling the bone defect with osteotropic material. This approach allowed us to reduce the rehabilitation period and further prosthetic treatment after 4-5 months, without additional bone grafting manipulations. Thus, the use of collagen osteotropic materials, possessing osteoconductive properties, can improve the treatment of patients with mandibular fractures.
\end{abstract}

Keywords: follicular cyst; fracture; mandible; osteosynthesis; mini-plate; collagenic xenograft; case report

\section{Introduction}

In clinical cases, when teeth are removed from the fracture line, and the bone defect is not filled, the risk of developing purulent inflammatory diseases increases.

The bone tissue can regenerate and change its micro- and macrostructure. Due to the delicate balance between the formation and loss of bone tissue, changes occur in the form of static and dynamic stress applied to the bone; if the applied stress is greater than the normal physiological level, the equilibrium is deflected towards osteoclasis (this relationship is known as Wolff's law of restructuring of bone structure). Nature has envisioned different types of mechanisms for bone repair after fractures to cope with the different mechanical environments surrounding the fracture. It is known that incomplete fractures (cracks), which only allow micro-movements between fracture fragments, heal with a small number of calluses along the fracture line, or without them (primary healing). In contrast to incomplete fractures, complete fractures are unstable and, therefore, generate macro displacement and heal with a large callus protruding from the sides of the bone (secondary tension) [1].

L.N. Hench (2007) identified the following four biomechanical stages of bone restoration after fracture [2-4]:

1st stage: at the site of the initial fracture, the bone does not function; it is characterized by low rigidity, resembling that of rubber. 
2nd stage: the bone does not function at the site of the original fracture, but there is hard tissue with great rigidity.

3rd stage: the bone is partially non-functional at the site of the original fracture, and on the unaffected part of the bone, there is hard tissue with high rigidity.

4th stage: the site of failure does not correspond to the site of the original fracture. Failure occurs with high rigidity.

These changes correspond to cellular changes, depending on the time and on the type of extracellular matrix at the site of tissue repair. The strength of the healing fracture increases significantly when mineralization of the osteoid occurs, approximately 4-6 months after the onset of healing.

The choice of treatment helps to prevent possible displacement of the bone fragments, which can delay, or interfere with, the healing of the fracture line.

Grafts of different nature are widely used in traumatology, oncology and surgery, as well as in oral and maxillofacial surgery $[5,6]$. There are specific requirements for the properties of grafts, such as biological compatibility, absence of unpleasant reactions (allergy and "transplant against host" reactions), availability, and others [5].

The "golden" standard for jaw reconstruction during bone plasty, guided bone regeneration, and dental implantation is considered to be an autograft, because of a combination of bone conductive ("matrix" role) and inductive (direct osteogenesis stimulation) properties [7]. Additionally, rather often, xenogenic materials (collagen, hydroxyapatites, and their combinations) are used, but they only possess bone conductive properties; however, in comparison, with autogenous materials, there is no need for new trauma creation, which is obligate for harvesting $[8,9]$.

However, the properties of pointed grafts have barely been studied for jaw fracture treatment. In addition, a fair amount of literature on the jaw fraction complications of harvesting can be found [10].

The aim of our case report was to improve the results of surgical treatment in a complicated mandibular fracture, with the use of collagenic xenograft during osteosynthesis.

\section{Materials and Methods}

The present case report followed the CARE guidelines. Patient, 39 years old, female (height- $178 \mathrm{~cm}$, weight- $58 \mathrm{~kg}$ ), was admitted to the Department of Maxillofacial Surgery of Sechenov University, with complaints of pain on the left side of the mandible, swelling of the left cheek, limited mouth opening, and malocclusion.

An extraoral physical exam revealed altered facial configuration due to soft tissue edema in the left buccal, parotid, and submandibular regions. The skin color was physiological. Pain and fragments of mobility at the left mandibular angle were noted during palpation. Regional lymph nodes were not enlarged. The mouth could open less than $20 \mathrm{~mm}$. There was no evidence of dysphagia. During intraoral checkup, lacerations and swelling of the mucosa around the left third lower molar were noted; the crown of the tooth was grossly decayed. Swallowing was free and painless. The occlusion was significantly altered due to fragment dislocations.

The orthopantomogram showed a fracture line in the area of tooth 3.8 and an ovalshaped area of radiolucency with teeth 3.7 and 3.8, with root involvement (Figure 1).

After a primary checkup and radiological evaluation, intermaxillary fixation was performed; the bite was stabilized with a physiological occlusion using arch bars and rubber elastics.

The patient was examined in a standard pre-surgical volume, using laboratory (blood and urine tests) and instrumental (EKG and chest X-ray) studies.

Multi-spiral computed tomography of the lower jaw determined an oval-shaped bone lesion at the root level of teeth 3.7 and 3.8, with dimensions of $20 \times 16 \times 16 \mathrm{~mm}$. The bone was swollen at the level of teeth 3.6-3.8, a periosteal reaction was noted, the contours of the jaw were enlarged, and the cortical plates were thinned. Pathological fracture of the lower 
jaw, with fragment displacement, occurred; the fracture line passed through the sockets of teeth 3.7 and 3.8 (Figure 2).

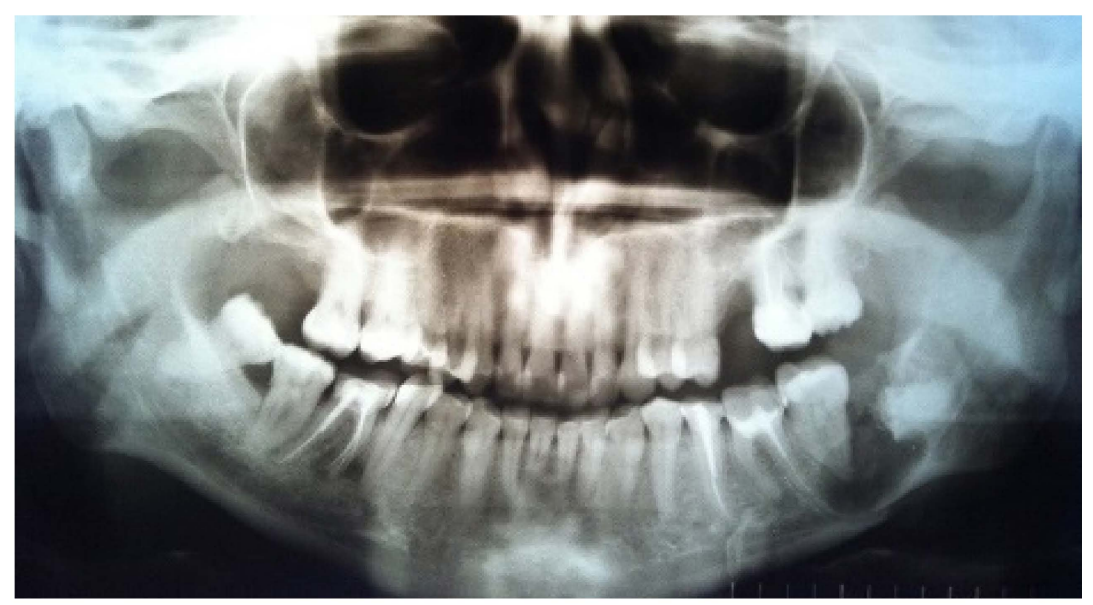

Figure 1. Orthopantomogram before surgery.

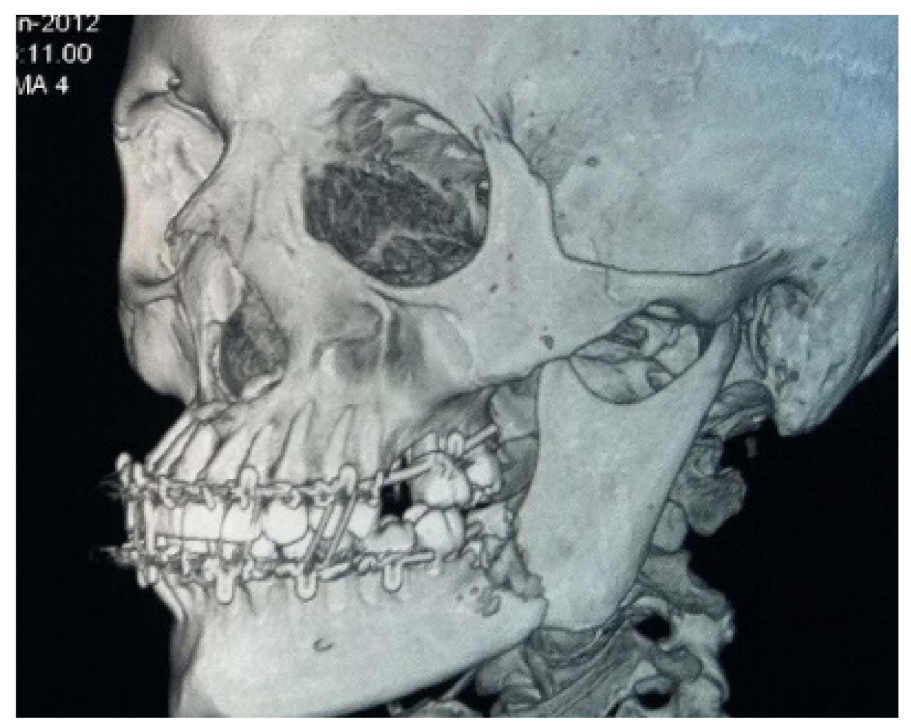

Figure 2. Patient's CBCT at admission.

Under general anesthesia (nasotracheal intubation), the patient underwent extraction of teeth 3.6, 3.7 and 3.8, cystectomy, and osteosynthesis. The angular fracture of the lower jaw was reduced and stabilized with two 6-hole titanium bone mini-plates and $10 \mathrm{~mm}$ miniscrews ("Conmet", Moscow, Russia). The bone defect was filled with xenograft "Collost" ("BIOPHARMHOLDING", Moscow, Russia). The external approach was chosen due to the prolonged violation of the integrity of the mucosa in the area of the fracture line, as well as the need to remove the cyst, reposition the fragments of the lower jaw, and fix them.

The patient was treated with "Collost" osteotropic material (xenogenic collagen osteotropic material, type I, with a 3D structure, obtained from the skin of cattle; "BIOPHARMHOLDING", Moscow, Russia). We used this material in the following 2 forms: 2 spheres (each $8 \mathrm{~mm}$ in diameter) and a membrane $(30 \times 20 \times 3 \mathrm{~mm}$ in size). According to the manufacturing company's instructions, the material was sterilized with all necessary methods for biological materials, and, in addition, with $\gamma$-radiation from a flacon. Before implantation in the wound, the material was placed in sterile saline at $25^{\circ} \mathrm{C}$ for $15 \mathrm{~min}$; the average volume increased by $20 \%$ for both the spheres and membranes. 


\section{Operation Technique}

Stage 1. Teeth 3.6, 3.7 and 3.8 were removed (Figure 3a).

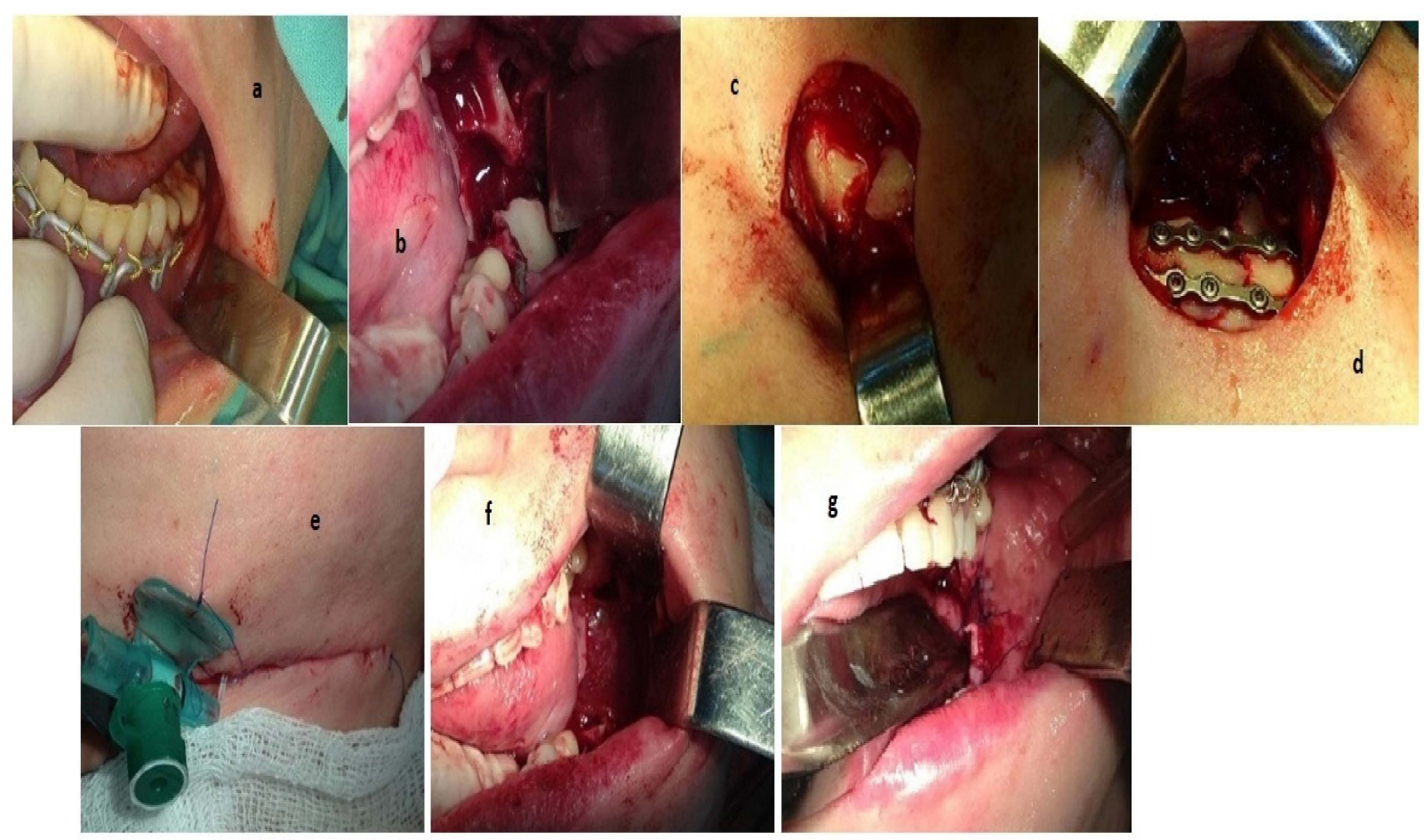

Figure 3. (a) Teeth 3.6, 3.7 and 3.8; (b) founded bone cavity and fracture line; (c) fracture line visualization; (d) osteosynthesis; (e) sutured skin after the intervention; (f) the membrane covers the graft and bone defect; $(\mathrm{g})$ imposed interrupted sutures in the area of the postoperative wound.

A bone cyst, $20 \times 15 \mathrm{~mm}$ in size, was determined. Cystectomy was performed and small bone fragments, $d=3 \times 5 \mathrm{~mm}$, were removed (Figure $3 \mathrm{~b}$ ).

Stage 2. After preliminary marking, an incision was made in the submandibular region on the left, departing from the edge of the lower jaw by $2.0 \mathrm{~cm}$, up to $2.5 \mathrm{~cm}$ long. The skin and subcutaneous fatty tissue were dissected in layers, $\mathrm{m}$. platysma, the own fascia of the neck. The body and the angle of the lower jaw on the left were skeletonized; a planar finely comminuted oblique fracture, with displacement of a smaller fragment upwards and inwards, and with a defect in the external cortical plate, was found (Figure 3c).

The fracture was reduced, and the bone fragments were stabilized in the correct position with two titanium 6-hole bone mini-plates and $10 \mathrm{~mm}$ titanium mini-screws (Figure 3d).

The wound was washed with antiseptic solution, layer-by-layer, and sutured with interrupted sutures using Vicryl 3.0 ("JOHNSON \& JOHNSON", Ethicon, Raritan, NJ, USA) threads. Intradermal suture was applied with Prolen 5.0 ("JOHNSON \& JOHNSON", Ethicon, Raritan, NJ, USA). A plastic catheter was placed at the fracture line (Figure 3e).

Stage 3. The intraoral operative wound was irrigated with antiseptic solution. The bone cavity was filled with collagen osteotropic material in the shapes of balls and threads. The graft was covered with a resorbable membrane (Figure 3f). The wound was sutured with Prolen 4.0 ("JOHNSON \& JOHNSON", Ethicon, Raritan, NJ, USA) interrupted sutures (Figure 3g).

Hemostasis was performed during surgery. The cyst walls were sent for histological analysis. 


\section{Results}

The postoperative period was uneventful. A course of antibacterial, anti-inflammatory, and analgesic therapy was carried out. Daily checkups were performed, with intraoral antiseptic solution irrigations. The antibiotic "lincomycin" (900 mg) was delivered to the fracture line through a catheter (Russia, Moscow LLC "Production of medicines") two times a day.

In the postoperative period, the protocol of antibiotic therapy included the following: intramuscular delivery of cefotaxime, $1.0 \mathrm{~g} \times$ two times per day; antihistamine (suprastin ("Egis", Budapest, Hungary) one tablet x one time per day); daily dressings; 0.05\% water chlorhexidine ("Ivanovo Pharmacologic Factory", Ivanovo, Russia) used to rinse three times per day. All treatments were performed for 7 days.

In the early postoperative period, a control panoramic view was made. The bone cavity, after extraction of the teeth and cystectomy, was visualized; titanium plates and screws were placed in the right positions. Additionally, the bone fragments were relocated into the correct position (Figure 4).

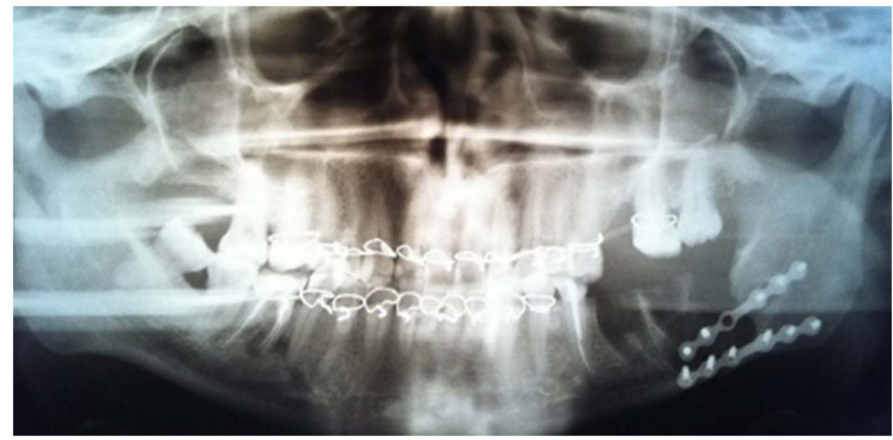

Figure 4. Patient orthopantomogram 1 day after surgery.

The results of the intraoperative histological examination showed that the follicular cyst remains.

After 7 years, the bone reparation process had finished. Furthermore, the patient had dental implant placements. The loss of dental implants is not related to the fracture that occurred more than 7 years ago. Due to improper loading of the installed orthopedic structures, bone resorption occurred (Figure 5).

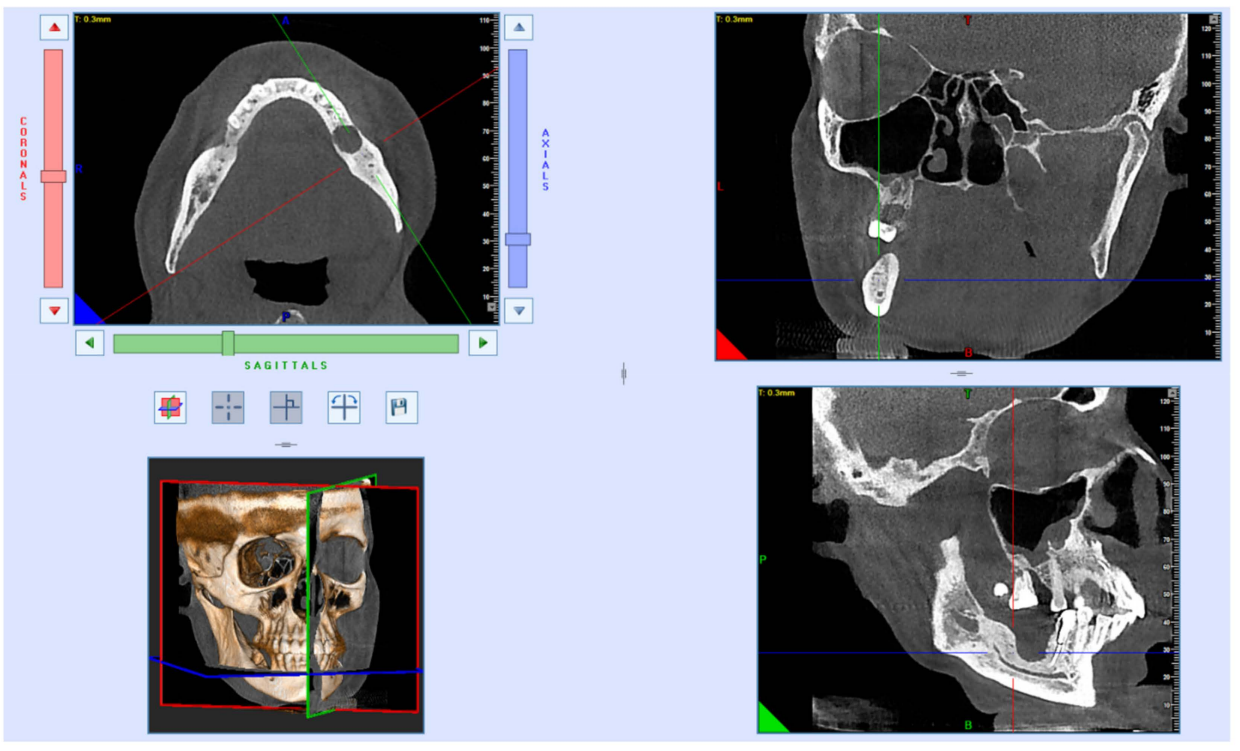

Figure 5. CT scan after dental implant loss before bone plasty 7 years after surgery. 
After removal of the dental implants that have undergone peri-implantitis, repeated CBCT examinations and prosthetics will be performed, considering the mechanical load and the peculiarities of the bite.

\section{Discussion}

According to the literature and our own experience, mandibular fractures are the most common fractures of the facial bones. Patients with fractured mandibles present with significant biting, chewing, and speaking function disorders [11]. The treatment of mandibular angle fractures presents a challenge, due to their higher rate of complications; there is currently no agreement on an optimal treatment [12]. Many studies show that patients with mandibular fractures demand an individual approach in the choice of treatment method, due to the possible combination of bone lesions of different nature, odontogenic infections, fractures in different areas of the mandible or facile skeleton, etc. [5-10,13]. In all these cases, a collagen osteotropic material was used to fill the bone defect. Even though the authors do not indicate the timing of full bone tissue regeneration, we can assume preliminary conclusions about the positive effect of the osteotropic material used in this study on the timing of full bone regeneration.

Currently, the mechanisms of bone regeneration are well studied, but there are several factors that affect, or delay, the bone healing process; some are inherent to the patient, others to the fracture itself, and others to the medical management of the patient. The size of the gap or bone defect is an important factor for the use of bone grafts, considering endochondral ossification [14,15].

Despite the high efficiency of modern methods of treatment, the bone tissue cannot be restored in full volume in all cases. For example, harvesting bone grafts from the anterior iliac crest for intraoral augmentation is a safe procedure for both young and elderly patients. Although a few cases of postoperative complications have been reported, such as gait disturbances, hypesthesia, scar formation, or delayed wound healing at the donor site, the incidence of these minor complications is low, and they mostly occur for a short duration. Major complications, such as fractures or incision hernias, are very rare. However, the volume of the bone graft was associated with a prolonged hospital stay, which should be considered when planning iliac crest bone graft procedures [16]. Therefore xenogenic materials are used to accelerate the reparative processes [17]. The basics of regeneration stimulation are laid in induction, conduction, and regeneration, due to the introduction of osteoprogenic cellular elements (stimulation by substitution). Every potency can be used to stimulate reparative osteogenesis, both independently and in combination [18].

Guided bone regeneration is a common method of treating bone defects of the jaws. The principles are based on a combination of bone graft materials and a barrier membrane, which covers and stabilizes the augmented zone. The results of H. Staedt et al.'s study showed that higher levels of enzyme activity indicate more intense bone remodeling. Furthermore, guided bone regeneration, with bone substitute particles and a collagen membrane, show desirable, significantly earlier bone remodeling activity, when compared to regeneration procedures with bone substitute particles only. The membrane potentially acts as a bioactive compartment, rather than just a passive barrier [19]. David S. Musson et al. concluded that bovine bone particulates offer a purely osteoconductive material, with no anabolic advantage. However, abundant growth factors clearly appear to produce an anabolic bone effect. In this regard, the development of new materials could provide a clear benefit for surgeons faced with large bone defects, which, if left, fail to heal and reduce the integrity of the surrounding bone [20].

In our study, a patient with a fracture of the mandible within the dentition was under observation for 8 years. The mandibular bone defect was filled with xenogenic bone material. The results of our study indicate a decrease in the timing of the osteoreparative processes and rehabilitation when using collagen osteotropic material in combination with a collagen membrane. With the use of osteotropic collagen material during the treatment of 
a patient with this clinical case, the healing and bone tissue regeneration period decreased from 6 to 5 months. No inflammatory processes were observed during the treatment.

However, in clinical practice, avoidance, by the dental surgeon or the maxillofacial surgeon, of filling the sockets of extracted teeth with osteotropic materials, especially when the fracture line passes through the dentition, can lead to the development of empty socket syndrome, infections and inflammatory complications, including posttraumatic osteomyelitis of the lower jaw. In addition, according to our data, the use of osteotropic material is also possible in cases of combined pathology of the lower jaw, when, because of surgical intervention, a rather large bone defect is formed, which requires filling, as in the case of our clinical example.

The use of osteotropic material with osteoconductive properties can improve the treatment outcome in patients with mandibular fractures within the dentition. This is due to the stabilization of the fracture line, a decrease in the likelihood of displacement of the fragments, along with fixation with devices, and a reduction in the time of bone tissue regeneration, which reduces the rehabilitation period and allows further orthopedic treatments of patients in $4-5$ months, without additional bone grafting operations. The acceleration of the bone reparative process allowed the patient to place dental implants in the area of the missing teeth after 8 years.

\section{Conclusions}

Osteotropic materials are a good option for jawbone reconstruction and can reduce the healing time in the area of the fracture line. Even in complicated mandibular fractures, in combination with a jaw cyst of various etiologies, osteotropic collagen materials provide favorable conditions for bone regeneration after simultaneous cystectomy and osteosynthesis, due to their osteoconductive properties. Such an approach allows for predictable fracture healing and dental implant placement in the future. However, further prospective clinical trials should be performed to determine the optimal treatment algorithms.

Author Contributions: Conceptualization, I.V.C. and L.D.A.; methodology, P.S.P.; investigation, E.Y.D.; resources, E.Y.D.; data curation, I.V.C.; writing—original draft preparation, E.Y.D.; writingreview and editing, I.V.C., L.D.A.; visualization, S.V.P.; project administration, S.V.P. All authors have read and agreed to the published version of the manuscript.

Funding: This research received no external funding.

Institutional Review Board Statement: The study was conducted in accordance with the Declaration of Helsinki and approved by the Institutional Ethics Committee of Sechenov University (protocol code 03-12, date of approval 28 November 2012).

Informed Consent Statement: Informed consent was obtained from a patient.

Data Availability Statement: Data are contained within the article.

Acknowledgments: We wish to express our appreciation to our colleagues and University. The research is supported within project 'Prioritet-2030'.

Conflicts of Interest: The authors declare no conflict of interest.

\section{References}

1. Sheen, J.R.; Garla, V.V. Fracture Healing Overview; StatPearls Publishing: Treasure Island, FL, USA, 2022. Available online: https://www.ncbi.nlm.nih.gov/books/NBK551678/ (accessed on 21 October 2021).

2. Reshetova, E.A.; Gucalova, A.A.; Lytkina, D.N. Obtaining and studying the properties of composite materials based on zincmodified hydroxyapatite and biodegradable polyesters. In Proceedings of the Perspectives Fundamental Sciences Development, Tomsk, Russia, 21-24 April 2020. Available online: http:/ /vital.lib.tsu.ru/vital/access/manager/Repository/koha:000563505 (accessed on 21 October 2021).

3. Mikhailyuta, A.G.; Sterleva, E.A.; Subbotin, I.G. Calcium-phosphate materials as biomaterials used in eliminating vicious defects. Alley Sci. 2020, 1, 79-84.

4. Balazic, M.; Kopac, J.; Jackson, M.J.; Ahmed, W. Review: Titanium and titanium alloy applications in medicine. Int. J. Nano Biomater. 2007, 1, 3-34. [CrossRef] 
5. Bohluli, B.; Mohammadi, E.; Oskui, I.Z.; Moaramnejad, N. Treatment of mandibular angle fracture: Revision of the basic principles. Chin. J. Traumatol. 2019, 22, 117-119. [CrossRef] [PubMed]

6. Bohner, L.; Beiglböck, F.; Schwipper, S.; Lustosa, R.M.; Pieirna Marino Segura, C.; Kleinheinz, J.; Jung, S. Treatment of Mandible Fractures Using a Miniplate System: A Retrospective Analysis. J. Clin. Med. 2020, 9, 2922. [CrossRef] [PubMed]

7. Efimov, Y.V.; Stomatov, D.V.; Efimova, E.Y.; Dolgova, I.V.; Stomatova, I.A. Treatment of patients with unilateral oblique fracture of the lower jaw. Sci. Eur. 2018, 24, 38-42.

8. Han, C.; Cui, J.; Zhang, X.; Li, K.; Liu, L. New surgical instrument for the treatment of condylar fractures: The digitized condylar retractor. Br. J. Oral Maxillofac. Surg. 2020, 58, 432-436. [CrossRef] [PubMed]

9. Sylvestre, A.M. Fractures of the Jaw. In Fracture Management for the Small Animal Practitioner; John Wiley \& Sons: Hoboken, NJ, USA, 2019; pp. 251-268. [CrossRef]

10. Ambarjan, G.M.; Karjagdyev, S.H. Analiz sushhestvujushih metodov lechenija perelomov nizhnej cheljusti. In Proceedings of the Aktual'nye Problem Razvitija Cheljustno-Licevoj Hirurgii na Territorii Povolzh'ja, Penza, Russia, 26 November 2020; pp. 46-51. Available online: http:/ / elib.pnzgu.ru/library/1606391059 (accessed on 22 October 2021).

11. Kumar, I.; Singh, V.; Bhagol, A.; Goel, M.; Gandhi, S. Supplemental maxillomandibular fixation with miniplate osteosynthesisrequired or not? Oral. Maxillofac. Surg. 2011, 15, 27-30. [CrossRef] [PubMed]

12. El-Anwar, M.W. Changing Trends in the Treatment of Mandibular Fracture. Int. Arch. Otorhinolaryngol. 2017, 22, 195-196. [CrossRef] [PubMed]

13. Khakimov, A.A. Comparison of methods for treating fractures of the lower jaw in the dentition. New Day Med. 2020, 2, 587-588.

14. Stock, S.R. The Mineral-Collagen Interface in Bone. Calcif. Tissue Int. 2015, 97, 262-280. [CrossRef] [PubMed]

15. Olate, S.; Vásquez, B.; Sandoval, C.; Vasconcellos, A.; Alister, J.P.; Del Sol, M. Histological Analysis of Bone Repair in Mandibular Body Osteotomy Using Internal Fixation System in Three Different Gaps without Bone Graft in an Animal Model. BioMed Res. Int. 2019, 2019, 8043510. [CrossRef] [PubMed]

16. Katz, M.; Ooms, M.; Heitzer, M.; Peters, F.; Winnand, P.; Kniha, K.; Möhlhenrich, S.; Hölzle, F.; Knobe, M.; Modabber, A. Postoperative Morbidity and Complications in Elderly Patients after Harvesting of Iliac Crest Bone Grafts. Medicina 2021, 57, 759. [CrossRef] [PubMed]

17. Thompson, E.M.; Matsiko, A.; Farrell, E.; Kelly, D.J.; O’Brien, F.J. Recapitulating endochondral ossification: A promising route to in vivo bone regeneration. J. Tissue Eng. Regen. Med. 2015, 9, 889-902. [CrossRef] [PubMed]

18. Torreggiani, E.; Matthews, B.G.; Pejda, S.; Matic, I.; Horowitz, M.C.; Grcevic, S.; Kalajzic, I. Preosteocytes/osteocytes have the potential to dedifferentiate becoming a source of osteoblasts. PLOS ONE 2013, 8, e75204. [CrossRef] [PubMed]

19. Staedt, H.; Dau, M.; Schiegnitz, E.; Thiem, D.G.E.; Tagadiuc, O.; Palarie, V.; Ottl, P.; Al-Nawas, B.; Kämmerer, P.W. A collagen membrane influences bone turnover marker in vivo after bone augmentation with xenogenic bone. Head Face Med. 2020, 16, 1-9. [CrossRef] [PubMed]

20. Musson, D.S.; Gao, R.; Watson, M.; Lin, J.-M.; Park, Y.-E.; Tuari, D.; Callon, K.E.; Zhu, M.; Dalbeth, N.; Naot, D.; et al. Bovine bone particulates containing bone anabolic factors as a potential xenogenic bone graft substitute. J. Orthop. Surg. Res. 2019, 14, 60. [CrossRef] [PubMed] 